\title{
Study the causes of pitting corrosion in carbon steel water pipeline at the site of advanced chemical industries complex
}

\author{
Haider Elbasher*, Khalid Omer*, Ahmed Eltyb Mustafa* \\ * Karary University, Khartoum, Sudan \\ Email: haider20ac@gmail.com
}

\begin{abstract}
There are many factors that affect pitting corrosion of carbon steel (Q235A) some of them related to the pipeline material such as material chemical composition specifications and other related to water specifications such as water temperature, $\mathrm{pH}$ of water and chemical and physical specification of water. In this study investigation was done for both water quality and materials of pipe lines (Q235A), four samples form on a piece of same rolled sheet welded pipe carbon steel (Q235A) were prepared and tested for chemicals composition, microstructure, roughness and thickness, the test results shown that no difference observed for all results only on one samples have difference roughness value near to the welded joint, these test applied for 4 piece took from one pipes to check the effect of rolling of these pipe that can cause dissimilarity .which enhance corrosion rates. Then the water quality investigated for temperature 45C, pH equal to 9, chloride, TDS and water pressure, the test result shown that the temperature of water was $45 \mathrm{C}^{\circ} \mathrm{pH} 9$ and contain chloride with concentration quite enough to initiate pitting. From the collected data this study specified the causes of pitting corrosion in the studied area of water pipe lines and summarized in the flowing, this pipe lines exposed to high pressure than the required, and temperature of water reach over $45 \mathrm{C}^{\circ}$ in summer, and chloride iron have main contribution on pitting corrosion of these pipes.
\end{abstract}

Key words-pitting corrosion, chloride iron, carbon steel, sulphate, passivation film

\section{INTRODUCTION}

Metals are extracted from their nature sources in the form of oxides and processed to be suitable for human needs in terms of tools, transportation, production machines, medicine and others. These metals are exposed to different environmentally condition causes losses in all aspects of it, because of the acceleration of corrosion which is defined as the destructive attack of a metal by chemical or electrochemical reaction with its environment [1], [2]. ACI (Advanced Chemical industries complex) stablished for producing propellant and explosives which depending on water as main firefighting medium, water supply for both production processes and firefighting is transport by network of carbon steel pipes (Q235A grade rolled welded sheet) which form closed loop to conserve the water pressure at all point of the loop. This pipeline loop was carried on overhead concrete racks, the length of these loop in total reaches 11,000 meters, and their diameters between 600 to $25 \mathrm{~mm}$. Recently in the year 2021 which is the 8th year of production we observed that these pipes corroded in different points, the risk assessment of this increasing of rate of corrosion can be described as catastrophic phenomena due to the loss of the water pressure suddenly by leaking which lead to firefighting systems failure. Due to the corrosion in these pipes which occurred in many areas in this network and is increasing with high rates, the site will be out of operation Therefore, it is necessary to conduct this study to distinguish the type and main cause of this type of corrosion after investigating all the factors that may lead to the corrosion under study. This study set strong foundation for selecting prevention and control of corrosion by spiffy the causes and type of corrosion to avoid both loss of workers, assets, and finance because the main reason of studying corrosion are include (i) human life and safety, (ii) the cost of corrosion, and (iii) conservation of materials. Internationally the losses in dollars estimated at about annual direct cost of corrosion in the United States at $\$ 276$ billion [1]. As literature review some studied conducted on effect of $\mathrm{pH}$ and TDS to measure specifics items that pointed from the starting of study this study done for general corrosion [3]. Other study investigates pitting corrosion in petroleum production also effect of Sulphur Reducing Bacteria [4]. Chloride effect on rubber was studied and determined threshold concentration of chloride [5]. Our study done for water from river Niles and network of carbon steel pipe after attacked and pitted to investigate the causes.

\section{STATEMENT OF THE PROBLEM}

It is noticeable that the rate of corrosion is steadily increasing in the overhead water transfer pipes in the Chemical Industries Complex in different locations and heights as in Fig. 1 and Fig. 2, and this is the beginning of a big problem that leads to anticipation of production or perhaps replacing entire lines at high costs. Therefore, this phenomenon must be studied in preparation for developing appropriate solutions.

\section{A. Objectives of this study}

The objectives of this study is summarized as follow.

1) To determine the type of corrosion in water pipelines at the site of advanced chemical industries complex.

2) To specify root cause of corrosion under study. 


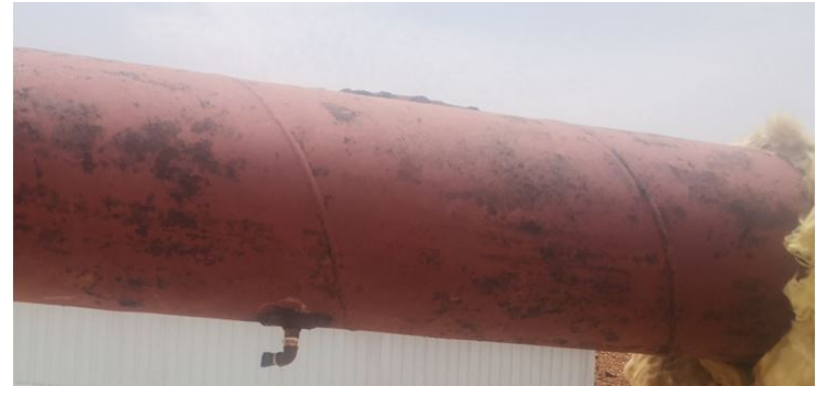

Fig. 1. Show the corrosion on pipelines location 1

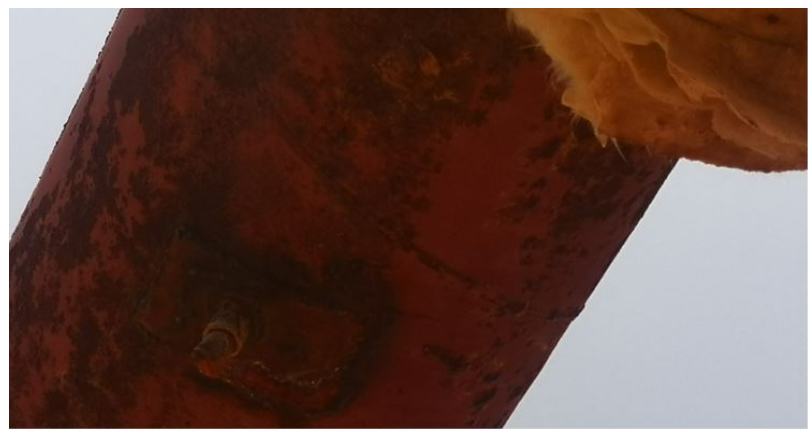

Fig. 2. Show the corrosion on pipelines location 2

\section{Methodology}

Physical check was done for all corroded point in the pipeline network To determine the type of corrosion.

The Steps below were conducted specify reason or reasons that cause this type of type of corrosion:

1) Corrosion types were studied.

2) Causes of the corrosion under observation were investigated.

3) Literatures about such problem were studied.

4) Water quality, flow rate and pressure inside these pipes tested.

5) Material of pipeline analyzed for roughness, microstructure and chemical composition to check dissimilarity.

\section{SURVEYING CONDUCTED}

Alisina Tolioei \& Vesselin \& Derek Northwood Found that low roughness value is more corrosion resistance. And used Deferent concentrations of $\mathrm{SO}_{4}^{-2}$ and $\mathrm{Cl}^{-1}$ ions $(10 \mathrm{ppm}$ $\left.\mathrm{Cl}^{-1}+5 \mathrm{ppm} \mathrm{SO}_{4}^{-2}\right),\left(10 \mathrm{ppm} \mathrm{Cl}^{-1}+10 \mathrm{ppm} \mathrm{SSO}-2\right.$ ) to prove that effect of chloride and sulfate ions have great effect of pit initiation growth [4]. Provides an effective aid for the dissemination of Engineering and science researches, inspiring interdisciplinary research cooperation to solve the problems related to the engineering and science fields and other study proved that Chloride ions penetrate the oxide film through pores or defect easier than other ions do such as $\mathrm{SO}_{4}^{-2}$. Break down of passivity occurs locally more than generally, and according to adsorption theory chloride ions adsorbs on the metal surface in competition with dissolved oxygen or hydroxides. The breakdown potential $(\mathrm{Eb})$ increase with temperature increase for deferent concentrations of chloride

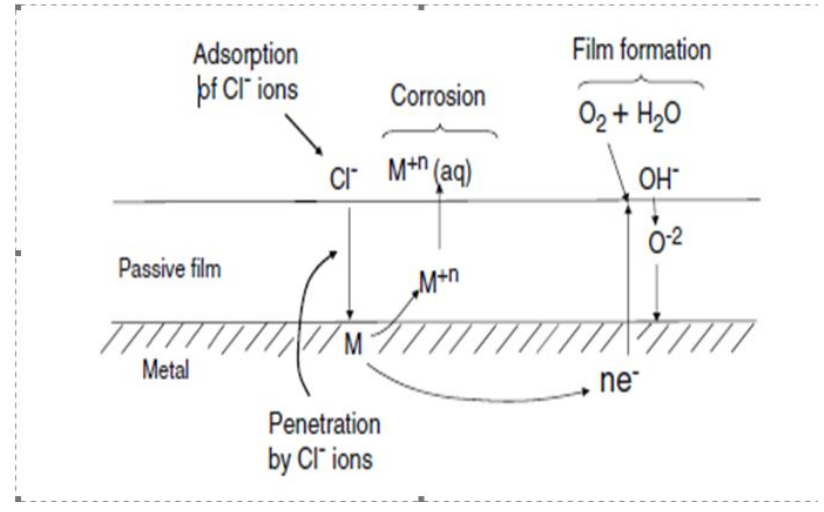

Fig. 3. Mechanism of penetrating passivation layer of metal [7]

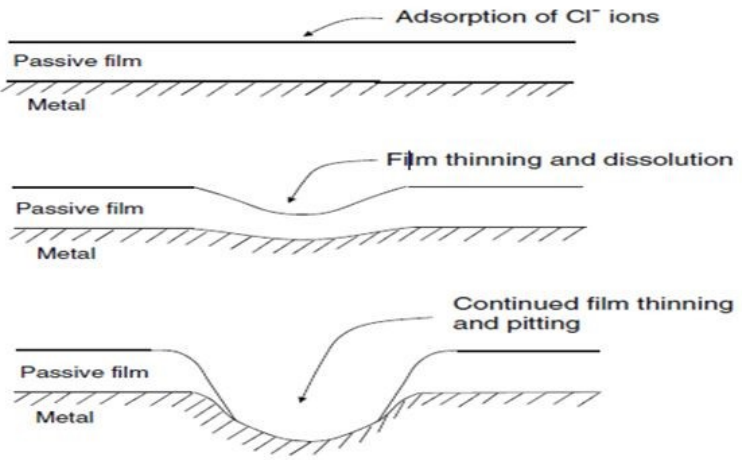

Fig. 4. Stage of pitting corrosion [9]

ions, when the temperature value reach $85 \mathrm{C}$ the relationship between $(\mathrm{Eb})$ and chloride ions concentration become linear and localized corrosion resistance decrease [4] thus:

$$
E_{\text {pit }}=A+K \log \left[C L^{-1}\right][6]
$$

Where:

$E_{\text {pit }}$ : pitting corrosion potential.

A \& K: parameter depend on temperature and sulphate concentration.

$\left[C L^{-1}\right]$ : chloride iron concentration.

$(\mathrm{Eb})$ : breakdown potential.

Chloride iron responsible for pitting corrosion. Pitting corrosion is a form of localized attack, it occurs when the protective film breaks in small isolated spots such as when halide salts contact [7] chloride iron initiates the pits by penetrate passivation film Fig. 3 so that:

Figure 4 explain the stages of pitting corrosion as fallow:

1) Adsorption.

2) Thinning.

3) Continue thinning and pitting as in Fig. 4 chloride have strong effect on penetrating passivity of carbon steel [8]. The effect of temperature studied and concluded that the increasing of temperature lower localized corrosion resistance [9].

Then Chloride iron attack carbon steel due to less affinity of oxygen and the type of corrosion only pitting corrosion. 
The commonly encountered soluble salts having the greatest effect on corrosion are the alkali chlorides, sulfates, nitrates, and sodium carbonate and bicarbonate. One process by which these salts can increase corrosion rates is by increasing the conductivity of water. Sulfate and chloride ions have especially great influences on the corrosion rate and type of corrosion [10].

\section{RESULTS}

\section{A. Micro structure results: fig 5,6,7and 8}

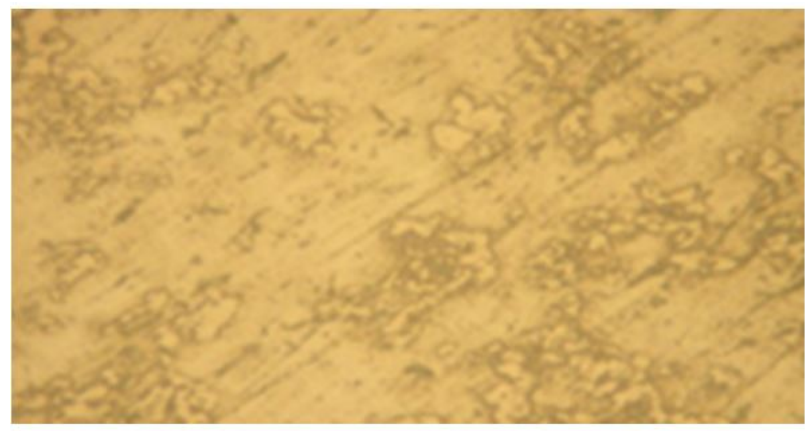

Fig. 5. microstructure of carbon steel sample No 1

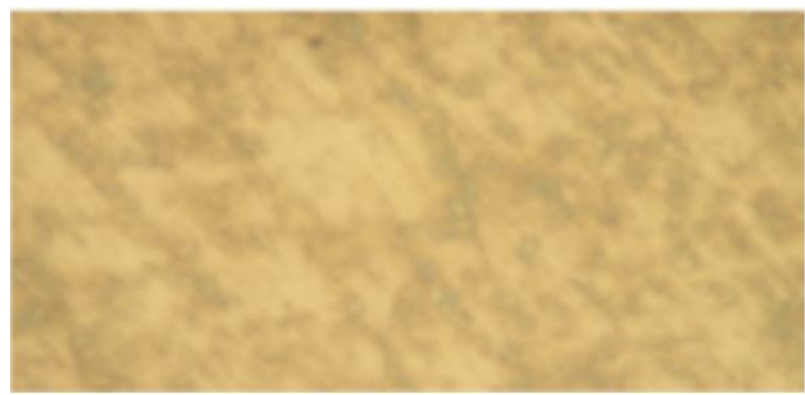

Fig. 6. microstructure of carbon steel sample No 2

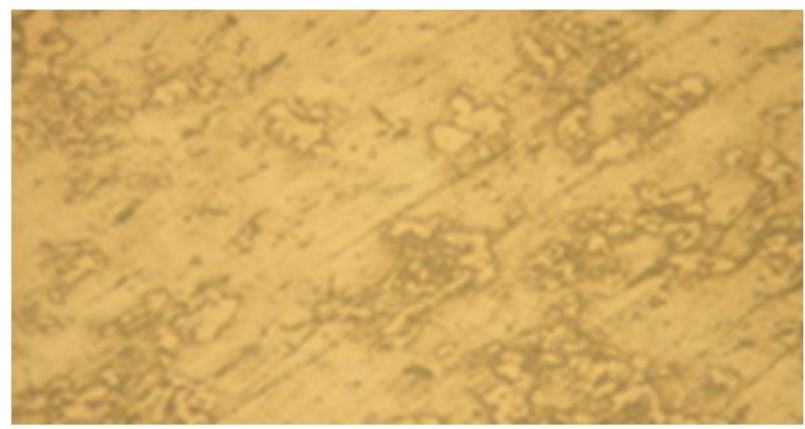

Fig. 7. microstructure of carbon steel sample No 3

\section{B. Roughness}

TABLE I shows similarity of samples according to analysis result report. For chemical properties of carbon steel see appendix A for all 4 samples and Chemical analysis for samples of Water quality analysis results in TABLE I, and mainly contain high chloride iron and sulphate items number 9 and 14.

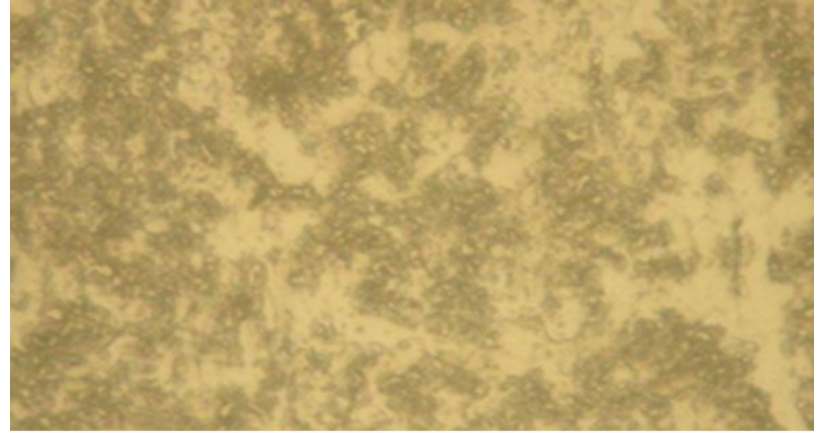

Fig. 8. microstructure of carbon steel sample No 4

TABLE I

SHOWS ROUGHNESS AND THICKNESS

\begin{tabular}{llll}
\hline \multirow{2}{*}{ items } & Samples No. & \\
& 1 & 2 & 4 \\
\hline Roughness & $6.3 \mu$ & $6.3 \mu$ & $6.3 \mu$ \\
thickness & $5.48 \mathrm{~mm}$ & $5.54 \mathrm{~mm}$ & $5.48 \mathrm{~mm}$ \\
\hline
\end{tabular}

TABLE II

WATER QUALITY TEST RESULT.

\begin{tabular}{llll}
\hline S/N & Parameter & Unit & Result \\
\hline $1-$ & $\mathrm{pH}$ & - & 7.84 to 9 \\
$2-$ & Total alkalinity & $\mathrm{mg} / \mathrm{l}$ & 90 \\
$3-$ & Total harness & $\mathrm{mg} / \mathrm{l}$ & 80 \\
$4-$ & TDS & $\mathrm{mg} / \mathrm{l}$ & 134 \\
$5-$ & Calcium & $\mathrm{mg} / 1$ & 29.6 \\
$6-$ & Magnesium & $\mathrm{mg} / 1$ & 1.44 \\
$7-$ & Total iron & $\mathrm{mg} / \mathrm{l}$ & 0.02 \\
$8-$ & Manganese & $\mathrm{mg} / \mathrm{l}$ & 0.014 \\
$9-$ & Chloride & $\mathrm{mg} / \mathrm{l}$ & 8 \\
$10-$ & Fluoride & $\mathrm{mg} / \mathrm{l}$ & 0.02 \\
$11-$ & Nitrogen-ammonia & $\mathrm{mg} / 1$ & 0.02 \\
$12-$ & Nitrate & $\mathrm{mg} / 1$ & 2 \\
$13-$ & Phosphate & $\mathrm{mg} / \mathrm{l}$ & 0.43 \\
$14-$ & sulphate & $\mathrm{mg} / \mathrm{l}$ & 9 \\
$15-$ & H.Sulfide & $\mathrm{mg} / \mathrm{l}$ & 0.006 \\
$16-$ & Copper & $\mathrm{mg} / \mathrm{l}$ & 0.001 \\
$17-$ & Aluminum & $\mathrm{mg} / \mathrm{l}$ & 0.011 \\
$18-$ & Turbidity & $\mathrm{NTU}$ & 0.46 \\
\hline
\end{tabular}

\section{CONCLUSION}

After physical checking the type of corrosion at Advanced chemical industrial complex is pitting corrosion from internal of the pipes and after testing water and analyzing material of pipeline with monitoring of maintenance this study concluded that:

1) Material of pipes Have met the standers of carbon steel Q235A according to test result report.

2) No dissimilarity of material either for roughness nor microstructure.

3) Microstructure not deformed by forming of pipe (the pipe was sheet rolled).

4) All previous studies and corrosion sciences proved the chloride iron responsible of such type of corrosion we have and by analyzing water which flow inside these 
pipes the result contains chloride iron with concertation of $8 \mathrm{ppm}$, so this prove the cause of pitting corrosion in water pipes with availably of high temperature of water which reach to over $45 \mathrm{C}^{\circ}$ and high pressure.

\section{RECOMMENDATIONS}

Further study must be conducted to:

1) Studying effect of temperature and $\mathrm{pH}$ of water on corrosion rate acceleration.

2) Studying relationship between dissolved oxygen (DO) in water and internal corrosion rate.

3) Study appropriate control for this type of corrosion by setting monitoring system to prevent catastrophic failure.

\section{REFERENCES}

[1] R. Revie and H.H.U., "Corrosion and corrosion control." Published simultaneously in Canada.

[2] M. G.Fontana, CORROSION ENGINEERING. MCc Graw-Hill book company, 3rd eddition ed.

[3] N. hasan, "Study the effect of ph and tds on the corrosion rate of carbon steel," ResearchGate.

[4] B. Jiaqiang Wei1, T. Wan1, K. Liu, S. Gong, and S. Junjie Wu1, "Effect of sulfate and chloride ions on pitting corrosion behavior of $2 \mathrm{cr} 12 \mathrm{mov}$ steel at ph 6 and 90 c," International Journal of ELECTROCHEMICALSCIENCE.

[5] Y. W. Hongze An 1, G.M., "Junyi wang 1, bin liu 1 and fuhui wang," in Study on the Chloride Threshold and Risk Assessment of Rebar Corrosion in Simulated Concrete Pore Solutions under Applied Potential. coatings.

[6] S. Wika, Pitting and Crevice Corrosion of StainlessSteel under Offshore Conditions. Norwegian University of Science and Technology2012.

[7] N. Obeyesekere. pitting corrosion, 2017,

[8] M. Deyab and S.T.K., "Cyclic voltammetric studies of carbon steel corrosion in chloride-formation water solution and effectof some inorganic salts."

[9] F. Samin Sharifi, Pin lu,Bruno Kusrten,Digby D.Macdonald. exploration of the effect of chloride iron concentration and temperature on pitting corrosion carbon steel in saturation of calcium hydroxide. ELSEVIER.

[10] J. N. Andre and J.R.C., "Corrosion of metallic pipes." 